\title{
Characterization of Coagulase-Negative Staphylococci Isolated from Hospitalized Patients in Narayana Medical College and Hospital Nellore, A.P. South India
}

\author{
Nadakuduru Premanadham*, Muni Lakshmi and B. Siva Prasad Reddy \\ Microbiology Department, NMC Nellore, India \\ *Corresponding author
}

\section{A B S T R A C T}

\section{Ke y w o r d s \\ Coagulasc-ncgative Staphylococci; Antimicrobial susceptibility; Nosocomiai infection.}

\section{Article Info}

Accepted: 12 April 2017 Available Online: 10 May 2017
Coagulase-negative staphylococci (CNS) are a main cause of nosocomial infection. The main purpose of this study was to determination of frequency of CNS isolates in in hospitalized patients and their susceptibility pattern to antimicrobial agents. During 11 months study, 147CNS clinical isolates were recovered from hospitalized patients in NMC $\&$ hospital Nellore south India. The age of patients was 10 t0 70yrs. In vitro susceptibility of isolates to 14 antimicrobial agents - ampicilin, oxacillin, cefexime. azithromycin, oflaxacin, clindamycin, amikacim, tegycyclin, vancomycin, tegycyclin. vancomycin, amoxicillin with clavalinic acid, Tycarcillin with clavalanic acid, piperacillin with tazobactum. sporflaxacin and linezolid was performed by Kirby-Bauer's Disk diffusion method according to Clinical and Laboratory Standards Institute (CLSl) criteria. Out of 147 patients were infected with CNS during study periodin different clinical specimens includes fifty four $(36.73 \%)$ were isolated from urine. Fifty three $(36.05 \%$.) from the pus 21(14.29\%) from sputum, 19(12.93\%) from blood samples. Most of CNS isolates were sensitive to linezolid $134(91.16 \%)$, tegycyclin $130(88.44 \%)$ and vancomycin $123(83.67 \%)$. Highest resistance seen cefexime 96(65.31), azythromycin 79(53.74\%), ampicillin 76(51.70\%) Multi-drug resistant CNS with reduced susceptibility to linezolid, vancomycin emerging pathogens of clinical concern. Monitoring of antibiotic resistance with attention to multi-resistant profile and aware to practitioners in the field is necessary.

\section{Introduction}

Nosocomial infections are important public health problems in developing countries as well as in developed countries. Nosocomial or hospital acquired infections are usually defined as infections that are identified at least 48-72 hours following admission to. hospital and health care facility (Ziebuhr et al., 2006). The most frequent types of nosocomial infections are bloodstream infection (BSI) urinary t1 act infection (UTI) pneumonia and surgical wound infection
Celik et al., 2005). Coagulase-negative staphylococci (CNS) are a group of microorganisms that known as normal biota of human skin and mucous membranes. CNS are consisting of 39 Species and 16 Species of them are known to cause infection in human.

Since 1970, CNS is recognized as important agents of a wide variety of human nosocomial infections. They account for 9\% of nosocomial infections (Piette et al., 2009). 
The two most frequently encountered CNS species in clinical samples are Staphylococcus epidermidis and Staphylococcus saprophyticus. Overall, S. epidermidis is the predominant agent in nosocomial infection, bacteremia, intravascular catheter-related infections, endocarditis, central nervous system shunt infections, urinary tract infections, ophthalmologic infections, dialysis related infections and surgical wounds while saprophyticus is more associated with urinary tract infections in females. Therefore, CNS isolates have received more attention recently as a cause of above mentioned infections (Guirguitzova et al., 2002). Accurate species level identification of CNS is expensive and time consuming according to past researchers, identification to species level is not necessary for good patient management and treatment (Heikens et al., 2005).

Nowadays the role of CNS as potential agents of nosocomial blood stream infections and UTI has been recognised CNS isolates account for $30 \%$ nosocomial blood stream infections. Among CNS isolates Staphylococcus epideimidis is most frequently associated with blood stream infection (Javadpour et al., 2010). The use of indwelling medical devices such. as central and peripheral venous catheters, artificial heart valves, valvular prostheses, pace-makers and orthopaedic prostheses in patients is the one of main predisposing agents $S$. epidermidis bacteremia (Stoll et al., 2002). UTI is one of the most frequent types of nosocomial infections and probably affects about one-half of all people during their lifetimes.

Many of clinicians are commonly encountered with UTIs in developing countries. UTI refer to the existence of microbial pathogens in the urinary tract and defined as the growth of a single pathogen of $>105$ colony-forming units per millilitre from properly collected mid-stream urine specimens (Barisic et al., 2003). UTIs are often caused by different bacteria. Bacterial agents are responsible for a spectrum of UTI that can be ranged from mild irritative voiding to bacteremic sepsis and death; UTIs can often be symptomatic or asymptomatic (Stamm et al., 2001).

The major causatives of UTIS are Escherichia coli and other Enterobactericae. Although relative frequency of the pathogens varies depending upon age, sex, catheterization and hospitalization but in complicated urinary tract infections and hospitalized patients, Gram negative rods complicated urinary tract infections and hospitalized patients, Gramnegative rods (Pseudomonas spp) and gram positive cocci (coagulase negative Staphylococci, Staphylococcus aureus, Streptococcus group B, Enterococci) are comparatively more common (Ronald, 2003).

Recently, in all over the world, resistance to antibiotics among CNS isolates has been reported. The infections associated with CNS requiring surveillance of antimicrobial therapy. In appropriate use of antimicrobial agents in treatment of patients recently has led to the spread of antimicrobial resistance among CNS isolates. On the other hand, widespread resistance among CNS isolates is major problem for the empirical treatment of nosocomial infections (Stamm et al., 2001; Ronald, 2009). During the past decade CNS isolates exhibited a remarkable ability "to rapidly develop antibiotic resistance. Areaspecific monitoring studies in order to detection of antimicrobial resistance patterns, effective treatment and decrease mortality rates is necessary.

Considering lack of information about antimicrobial resistance profiles of CNS clinical isolates and increasing infections, the object of this study was to investigate the 
frequency of CNS isolates in hospitalized patients and their susceptibility pattern to commonly used antimicrobial agents.

\section{Materials and Methods}

\section{Bacterial Isolates}

The present descriptive study was performed on cases who were hospitalized in different wards of hospital. A total of 147 clinically significant CNS isolates from different clinical samples for a period of 11 months (from Jun 2014 to May 2015) CNSs were isolated from sputum, blood, pus, and urine samples. Isolates were diagnosed as true pathogen when isolated in pure culture from infected sites. UTI refer to the existence of microbial pathogens in the urinary tract and defined as the growth of a single pathogen of $>10$ colony-forming units per milliliter (CPU/ml) from. properly collected midstream urine specimens. All the cases had history of nosocomial infection and clinical examination was conducted by physician to exclude community-acquired infections.

The plates were incubated in aerobic conditions at $37^{\circ} \mathrm{C}$ for $24-48$ hours. Negative cultures were maintained $1 \mathrm{n}$ incubator up to 2 days. Identification of specimens was performed by Grams staining, catalase, manitol fermentation and coagulase tests and other conventional biochemical tests. Coagulase test was done both slide and tube methods (Clinical and Laboratory Standards Institute, 2012). Samples confirmed as a CNS isolates were stored in Tryptic Soy Broth containing $20 \%$ glycerol at $70^{\circ} \mathrm{C}$ and were subjected to further investigation

\section{Antimicrobial susceptibility testing}

To evaluate antimicrobial susceptibility of isolates Kirby-Baue1's Disk diffusion method was done according Clinical Laboratory and
Standards Institute (CLSI; formerly National Committee for Clinical Laboratory Standards) criteria (Ghadiri et al., 2012). The following antimicrobial agents were used in this study: Ampicilin; oxacillin Cefexime; azithromycin, oflaxacin, amicacin tegycyclin, vancomycin, clindamycine, amoxicillin with clavulanic acid, ticarcillin with clavalinic acid, pippercillin with tazobactum, sporflaxacin, linazolid.

Briefly, the bacterial suspension obtained from overnight cultures. The turbidity of each bacterial suspension was adjusted equivalent to a no. $0.5 \mathrm{McF}$ arland standard and then inoculated on Mueller-Hinton agar Diameter of inhibition zones was measured after incubation at $35^{\circ} \mathrm{C}$ for $18-24$ hours, and data were reported as susceptible and resistance

\section{Results and Discussion}

Over a period of 11 months study CNS accounts for 147 isolates in hospitalized patients. The age range of the patients was from 2 to 70 years. 147 isolates of which there were $67(45.58 \%)$ females and 80 $(54.42 \%)$ males as shown in table 1.

Occurrence of infection with CNS was highest in the age group 40 to 49 year $29(19.73 \%)$ and the lowest in the age less than 10 years $3(2.04 \%)$

In males, majority of the CNS found in the age group 50 to 59 years $19(12.93 \%$ ) and in females age group 20 to 29 years $17(11.56 \%)$. Frequency of CNS in different age groups is shown in table 2

No much significant difference was found between isolated bacteria and age of the patients

Among 147 isolates of CNS, 54(36.73 \%) were isolated from the urine $53(36.055 \%)$ 
from pus, 21(14.29\%) from sputum and $19(12.93 \%)$ from blood sample. High \% of isolates are from urine followed by pus, sputum and blood as shown in table 3 .

All isolates of CNS were negative for free and tube coagulase.

The profile of isolated bacterial showed wide different level of resistance for tested antibiotics (Data are shown in table 4). Antibiotic susceptibility testing of the isolates showed maximum resistance cefexime 93(65.31\%) azytromycin 79(53.74\%) ampicillin $76 \quad(51.70 \%)$ followed by clindamycin 47 (31,97\%). Oxacillin 43 (29.25\%), tecarcillin with clavulanic acid 43 (29.25\%), amoxicillin with clavulanic acid 40 (27.21\%), sporflaxacin 34(23.13\%), amikacin $31(21.09 \%)$. oflaxacin 30(20.14\%).

Most of the isolates were sensitive to linazolid, tygycyclin, vancomycin.

Multidrug resistant (MDR) was defined as resistance to at least three or more antibiotics.

Nosocomial infection is a global problem that affects both developed and developing countries. Recent studies have revealed the importance of CNS as one of the causes of nosocomial or healthcare related infections. Many of nosocomial infections are associated with microorganisms that are resistant to antibiotics and can easily spread by hospital environment and personnel. Monitoring of antimicrobial susceptibility can aid to clinicians for prescript appropriate antibiotics and prevent the development of drug resistance (Cleven et al., 2006). Effective treatment of patients with UTI and blood stream infections associated with CNS commonly relays on the identification of the type of organisms and the selection of an effective antibiotic agent to the organism in question. The pattern of antimicrobial resistance of CNS producing infection varies in different regions and especially different wards. In this study, the frequency of CNS isolated from hospitalized patients are 67(45.58\%) females and 80 (54.42\%) males. Among different clinical samples, CNS isolates were isolated from $54(36.73 \%)$ urine samples followed by pus 53(36.05\%) sputum $21(14 ; 29 \%)$ and blood 19(12.93\%). CNS isolated from urine $54(36.73 \%)$ is highest. This result is consistent with the results of recent studies in India (Asangi, 2011; Sarathbabu et al., 2011). In a study done by Vaez et al., in 2012, CNS was mostly isolated from blood cultures that are in contrary with our study (nellore). In another study done by Banelj et al., 72 of 150 strains of CNS (60\%) were isolated from blood samples, 36(24\%) from pus samples, 15(10\%) from urinary catheter tip and 12(8\%) from the urine samples. The sex distribution of patients in our study female was between 20 to 49 years. This result is similar to those reported from many other researchers.

In this study, we investigated the frequency and antimicrobial susceptibility patterns of CNS isolated This study revealed that all of CNS isolates were mostly sensitive to linazolid, tegycyclin and vancomycin. Our finding about vancomycin is in accordance with: studies done in India 2012, Spain 2002, England 2004, Asia Pacific region 2007, USA 2007 and Turkey 2007 (Cuevas et al., 1986; Reynolds et al., 2002).

In our study, the highest resistance rate of the CNS was against cefexime 9365.31(\%) followed by azytromycin 79(53.74\%) ampicillin 76(51.70\%) followed by clindamycin $\quad 47(31,97 \%)$ Oxacillin $43(29.25 \%)$, tecarcillin with clavulanic acid 43(29.25\%), amoxicillin with clavulanic acid 40(27.21\%), sporflaxacin 34(23.13\%), amicacin 31(21.09\%), oflaxacin 30(20.14\%). 
This study correlates with a study by Asangi et al., where the antibiotic susceptibility testing showed maximum resistance to ampicillin. In study Sader et al., (2007) $85^{\circ} 0$ $95 \%$ of CNS were resistance to ampicillin and penicillin. High resistances to these antibiotics have been reported by several researchers. Resistance to ampicillin, cefexime azithromycin, among our isolates may related to improper usage of this antibiotic for treatment of other infections, increase use of other beta lactam antibiotics in hospital and acquisition of resistant during hospitalization.

Resistances to Eryrhromycin (azytrornycin) have been reported differently by several researchers. In Spain, resistance to
Erythromycin (azythromycin) increased progressively in CNS from 41\% in 1986 to 63\% in 2002 (20). Asangi et al., showed high level of resistance to erythromycin among CNS isolates. In two surveillance studies, performed in 2006, in US and Europe CNS isolates had increased resistance rate to erythromycin (Jones et al., 2006). The possible reasons of high resistant rate to erythromycin may be related to use of erythromycin in treatment of disease caused by CNS and common infections, increase exposure of this isolates to new macrolide, efflux of the drug and ribosomal methylation. Cross resistance between clindamycin and macrolides is well described by several investigators.

Table.1 Sex wise distribution

\begin{tabular}{|l|l|}
\hline Total male & $80(54.42 \%)$ \\
\hline Total female & $67(45.58 \%)$ \\
\hline Total & $147(100.00 \%)$ \\
\hline
\end{tabular}

Table.2 Age wise distribution

\begin{tabular}{|l|c|c|c|c|c|c|}
\hline AGE & MALE & $\mathbf{\%}$ & FEMAIL & \% & TOTAL & \% \\
\hline$<\mathbf{1 0}$ & $\mathbf{2}$ & $\mathbf{1 . 3 6 \%}$ & $\mathbf{1}$ & $\mathbf{0 . 6 8 \%}$ & $\mathbf{3}$ & $\mathbf{2 . 0 4 \%}$ \\
\hline 10 TO 19 & 5 & $3.40 \%$ & 4 & $2.72 \%$ & 9 & $6.12 \%$ \\
\hline 20 TO 29 & 8 & $5.44 \%$ & 17 & $11.56 \%$ & 25 & $17.01 \%$ \\
\hline 30 TO 39 & 11 & $7.48 \%$ & 6 & $4.08 \%$ & 17 & $11.56 \%$ \\
\hline 40 TO 49 & 14 & $9.52 \%$ & 15 & $10.20 \%$ & 29 & $19.73 \%$ \\
\hline 50 TO 59 & 19 & $12.93 \%$ & 8 & $5.44 \%$ & 27 & $18.37 \%$ \\
\hline 60 TO 69 & 13 & $8.84 \%$ & 10 & $6.80 \%$ & 23 & $15.65 \%$ \\
\hline$>70$ & 8 & $5.44 \%$ & 6 & $4.08 \%$ & 14 & $9.52 \%$ \\
\hline
\end{tabular}

Table.3 Sample wise distribution

\begin{tabular}{|l|l|l|}
\hline Blood & 19 & $12.93 \%$ \\
\hline Pus & 53 & $36.05 \%$ \\
\hline Sputam & 21 & $14.29 \%$ \\
\hline Urine & 54 & $36.73 \%$ \\
\hline Total & 147 & $100.00 \%$ \\
\hline
\end{tabular}


Table.4 Results of antibiotic susceptible test

\begin{tabular}{|l|l|r|r|r|}
\hline S.No. & Antibiotics & \multicolumn{1}{l|}{$\begin{array}{l}\text { No of } \\
\text { resistance }\end{array}$} & \multicolumn{1}{l|}{ No of susceptibility } & \multicolumn{1}{l|}{ Total } \\
\hline 1 & Ampicillin & $76(51.70 \%)$ & $71(48.30 \%)$ & $100.00 \%$ \\
\hline 2 & Oxacillin & $43(29.25 \%)$ & $104(70.75 \%)$ & $100.00 \%$ \\
\hline 3 & Cefixime & $96(65.31 \%)$ & $51(34.69 \%)$ & $100.00 \%$ \\
\hline 4 & Azithromycin & $79(53.74 \%)$ & $68(46.26 \%)$ & $100.00 \%$ \\
\hline 5 & Ofloxacin & $30(29.47 \%)$ & $117(79.59 \%)$ & $100.00 \%$ \\
\hline 6 & Clindamycin & $47(31.97 \%)$ & $100(68.03 \%)$ & \\
\hline 7 & Amikacin & $31(21.09 \%)$ & $116(78.91 \%)$ & $100.00 \%$ \\
\hline 8 & Tegycycline & $17(11.56 \%)$ & $130(88.44 \%)$ & $100.00 \%$ \\
\hline 9 & Vancomycin & $24(16.33 \%)$ & $123(83.67 \%)$ & $100.00 \%$ \\
\hline 10 & Amoxycillin+Clavulanic Acid & $40(27.21 \%)$ & $107(72.79 .03 \%)$ & $100.00 \%$ \\
\hline 11 & Ticrcillin with Clavlanicacid & $43(29.25 \%)$ & $104(70.75 \%)$ & $100.00 \%$ \\
\hline 12 & Piperacillin+Tazobactam & $28(19.05 \%)$ & $119(80.95 \%)$ & $100.00 \%$ \\
\hline 13 & Sparfloxacin & $34(23.13 \%)$ & $113(76.87 \%)$ & $100.00 \%$ \\
\hline 14 & Linezolid & $13(8.84 \%))$ & $134(91.16 \%)$ & $100.00 \%$ \\
\hline
\end{tabular}

The resistance rate to linzolide was $8.84 \%$ in our study. US and Turkey, Englans, Australia and Irland linazolid resistance is higher (Biedenbach et al., 2007). The resistance rate to gentamicin in among CNS isolates was higher than other studies (Zia et al., 2010; Khorshidi et al., 2003). The data from our investigation exhibited that ampicillin, penicillin, cefoxime, cefalotin, gentamycin, oxacillin and erythromycin had not good activity against CNS isolates.

It should not be ignored that MDR strains of CNS can serve as a reservoir of resistance genes and can spread to the other microorganisms. Therefore, in order to prevent further spread of multi-drug resistant CNS, the use of antibiotics should be monitored and implementation of infection control. In the other hand, continued use of antibiotic for treatment of infections associated with CNS isolates should be supported by monitoring of antimicrobial susceptibility to prevent the spread of resistant isolates and also eliminate the use of antibiotics for a prolonged period. Resistant to linzolid tegycycline and vancomycin has seen minimum among our isolates it seems that them can be effective drugs for treatment of infections associated with CNS isolates. According to our findings, ampicillin, penicillin, cefoxitin, gentamicin, and erythromycin are not effective drugs for treatment of infections associated with CNS. Progressive increase in resistant to these antibiotics and multiple resistances in present study, may be related to increased usage of these antibiotics for treatment and also ability of strains in acquisition of resistance genes to other organisms of different species. Our investigation also exhibited that use of linzolid in order to decrease spread of resistance gene among CNS isolates must be revised.

In conclusion, high level of resistance among CNS isolates limits the use of antimicrobial Agents for therapy and also the spread of 
MDR isolates is threat for hospitalized patients. Continuous surveillance for multidrug resistant strains is necessary to prevent the further spread of resistant isolates.

\section{References}

Asangi, S.Y. 2011. Speciation of clinically significant coagulase negative staphylococci and their antibiotic resistant patterns in a tertiary care hospital. Int. J. Biol. Med. Res., 2(3): 735-739.

Barisic, Z., Babic-Erceg, A., Borzic, E., Zoranic, V., Kaliterna, V., Carev, M. 2003. Urinary tract infections in South Croatia: Etiology and antimicrobial resistance. Int. J. Antimicrob. Agents, 22 Suppl 2: 61-4.

Biedenbach, D.J., Bell, J.M., Sader, H.S., Fritsche, T.R., Jones, R.N., Turnidge, J.D. 2007. Antimicrobial susceptibility of Gram-positive bacterial isolates from the Asia-Pacific region and an in vitro evaluation of the bactericidal activity of daptomycin, vancomycin, and teicoplanin: a SENTRY Program Report (2003-2004). Int. J. Antimicrobial Agents, 30(2): 143-9.

Celik, I., Inci, N., Denk, A., Sevim, E,, Yasar, D., Yasar, M. 2005. Prevalence of Hospital acquired infections in Anesthesiology intensive care unit," Firat Tip Dergisi., 10(3): 132-5.

Cleven, B.E., Palka-Santini, M., Gielen, J., Meembor, S., Krönke, M., Krut, O. 2006. Identification and characterization of bacterial pathogens causing bloodstream infections by DNA microarray. J. Clin. Microbiol., 44(7): 2389-97.

Clinical and Laboratory Standards Institute. 2012. Supplemental tables. Performance standards for antimicrobial susceptibility testing; fifteenth informational supplement. CLSI Publication M100 S15, M2-A11 and M07-A9.Pennsylvania: CLSI.

Cuevas, O., Cercenado, E., Vindel, A., Guinea, J., Sanchez-Conde, M., Sanchez-
Somolinos, M., et al. 2004. Evolution of the antimicrobial resistance of Staphylococcus spp. in Spain: five nationwide prevalence studies, 1986 to 2002. Antimicrob. Agents Chemother., 48: 4240-5.

Euzeby, J.P. 2014. LSPN List of prokaryotic names with standing in nomenclature. http://www.bacterio.cict.fr/. J. Paramed. Sci. (JPS) Spring, Vol.5, No.2 ISSN 2008-4978 49

Forbes, B.A., Sahm, D.F., Weissfeld, A.S. 2007. Bailey and Scott's Diagnostic microbiology, 12th edition, Mosby Elsevier, 842-55.

Ghadiri, H., Vaez, H., Khosravi, S., Soleymani, E. 2012. The antibiotic resistance profiles of bacterial strains isolated from patients with hospital-acquired bloodstream and urinary tract infections. Critical Care Res. Practice.

Guirguitzova, B., Chankova, D., Zozikov, B. 2002. Staphylococci as uropathogens frequency of isolation in hospitalized patients and sensitivity to antimicrobial agents. Ann. Urol., 36: 341-7.

Heikens, E., Fleer, A., Paauw, A., Florijn, A.C., Fluit, A. 2005. Comparison of genotypic and phenotypic methods for species-level identification of clinical isolates of coagulase-negative staphylococci. J. Clin. Microbiol., 43: 2286-90.

Javadpour, S., Karimi, E., Karmostaji, A. 2010. Frequency and anti-biogram pattern of coagulase negative Staphylococcus in clinical specimens of Shahid Mohammadi Hospital in patients, Bandar-Abbas, Iran. African J. Microbiol. Res., 4(14): 1581-3.

Jones, R.N., Fritsche, T.R., Sader, H.S., Ross, J.E. 2006. LEADER surveillance program results for 2006: an activity and spectrum analysis of linezolid using clinical isolates from the United States (50 medical centers). Diag. Microbiol. Infect. Dis., 59(3): 309-17.

Jones, R.N., Fritsche, T.R., Sader, H.S., Ross, J.E. 2006. Zyvox® Annual Appraisal of Potency and Spectrum Program results for 2006: an activity and spectrum 
analysis of linezolid using clinical isolates from 16 countries. Diag. Microbiol Infectious dis., 59(2):199-209.

Khorshidi, A., Moniri, R., Shajari, G. 2003. Antimicrobial Resistance in Gramnegative Bacilli Isolated from Urinary Tracts Infections. Arch. Razi Ins., 55.

Koksal, F., Yasar, H., Samasti, M. 2009. Antibiotic resistance patterns of coagulase-negative staphylococcus strains isolated from blood cultures of septicemic patients in Turkey. Microbiol. Res., 164(4): 404-10.

Piette, A., Verschraegen, G. 2009. Role of coagulase-negative staphylococci in human disease. Vet. Microbiol., 134: 4554.

Prais, D., Straussberg, R., Avitzur, Y., Nussinovitch, M., Harel, L., Amir, J. 2003. Bacterial susceptibility to oral antibiotics in community acquired urinary tract infection. Arch. Dis. Child, 88(3): 215-8.

Reynolds, R., Potz, N., Colman, M., Williams, A., Livermore, D., MacGowan, A. 2004. Antimicrobial susceptibility of the pathogens of bacteraemia in the UK and Ireland 2001-2002: the BSAC Bacteraemia Resistance Surveillance Programme. J. Antimicrobial Chemother., 53(6): 1018-32.

Ronald, A. 2003. The etiology of urinary tract infection: Traditional and emerging pathogens. Dis Mon., 49(2): 71-82.

Sader, H.S., Watters, A.A., Fritsche, T.R., Jones, R.N. 2007. Daptomycin antimicrobial activity tested, J. Paramed. Sci. (JPS) Spring, Vol.5, No.2 ISSN 2008-
497850 against methicillin-resistant staphylococci and vancomycin-resistant enterococci isolated in European medical centers BMC Infectious Dis., 7(1): 29.

Sarathbabu, R., Rajkumari, N., Ramani, T.V. 2011. Characterization of Coagulase negative Staphylococci isolated from urine, pus, sputum and blood samples. IJPSI, 2(1): 37-46.

Singh, S., Banerjee, G., Agarwal, S., Kumar, M., Singh, R. 2008. Simple method for speciation of clinically significant coagulase negative Staphylococci and its antibiotic sensitivity/resistant pattern in NICU of tertiary care centre. Biomed. Res., 19(2): 97-101.

Stamm, W.E., Norrby, S.R. 2001. Urinary tract infections: disease panorama and challenges. J. Infect. Dis., 183: Suppl 1: S1-4.

Stoll, B.J., Hansen, N., Fanaroff, A.A., Wright, L.L., Carlo, W.A., Ehrenkranz, R.A., et al. 2002. Late-onset sepsis in very low birth weight neonates: the experience of the NICHD Neonatal Research Network. Pediatrics, 110(2): 285-91.

Zia Sheikholeslami, N., Hassanshahi, G. 2010. The frequency of coagulase negative Staphylococci urinary tract infections with antimicrobial resistance pattern in Rafsanjan. Pak. J. Med. Sci., 26(1): 10710.

Ziebuhr, W., Hennig, S., Eckart, M., Kränzler, H., Batzilla, C., Kozitskaya, S. 2006. Nosocomial infections by Staphylococcus epidermidis: how a commensal bacterium turns into a pathogen. Int. J. Antimicrob. Agents.

\section{How to cite this article:}

Nadakuduru Premanadham, Muni Lakshmi and Siva Prasad Reddy, B. 2017. Characterization of Coagulase-Negative Staphylococci Isolated from Hospitalized Patients in Narayana Medical College and Hospital Nellore, A.P. South India. Int.J.Curr.Microbiol.App.Sci. 6(5): 1034-1041. doi: https://doi.org/10.20546/ijcmas.2017.605.112 